\title{
Tweeting Alone? An Analysis of Bridging and Bonding Social Capital in Online Networks
}

\author{
Javier Sajuria ${ }^{1}$, Jennifer vanHeerde-Hudson ${ }^{1}$, David \\ Hudson $^{1}$, Niheer Dasandi $^{1}$, and Yannis Theocharis ${ }^{2}$
}

\begin{abstract}
In this article, we test Putnam's claim that online interactions are unable to foster social capital by examining the formation of bridging and bonding social capital in online networks. Using Burt's concepts of closure and brokerage as indicators, we observe networks formed through online interactions and test them against several theoretical models. We test Putnam's claim using Twitter data from three events: the Occupy movement in 2011, the IF Campaign in 2013, and the Chilean Presidential Election of the same year. Our results provide the first evidence that online networks are able to produce the structural features of social capital. In the case of bonding social capital, online ties are more effective in forming close networks than theory predicts. However, bridging social capital is observed under certain conditions, for example, in the presence of organizations and professional brokers. This latter finding provides additional evidence for the argument that social capital follows similar patterns online and offline.
\end{abstract}

\section{Keywords}

social capital, Twitter, network simulation, closure, brokerage, social media

\section{Introduction}

Putnam's (2001) thesis outlining the decline of social capital in the United States re-invigorated one of the most enduring debates and research agendas

${ }^{1}$ University College London, UK

${ }^{2}$ University of Mannheim, Germany

Corresponding Author:

Javier Sajuria, University College London, 29/31 Tavistock Square, London WC1H 9QU, UK.

Email: j.sajuria@ucl.ac.uk 
in political science and elsewhere. His central argument that social connections are vital for the sustainability and stability of a democratic society elevated social capital from the individual or group level of analysis (Putnam, 1994, 2001) to an understanding of how social capital affects political institutions. His thesis has been taken up by scholars studying social capital in a variety of national contexts (Bowles \& Gintis, 2002; Colletta \& Cullen, 2000; Claridge, 2004; Hooghe \& Stolle, 2003; Pinchotti \& Verwimp, 2007) and has been subject to numerous revisions and rejoinders (Sobel, 2002; Tzanakis, 2013). Twenty years on from Putnam's initial publication, the debate over social capital shows no sign of abating, instead taking on a new dimension - the development of information and communication technologies (ICTs).

The explosion of ICTs has transformed inter-personal communications and, consequently, has affected the ways in which people create and maintain social connections. In particular, social media has brought new questions to the field of social capital and, despite widespread interest, the literature has not always kept pace. Work in this field has focused primarily on understanding the role of social connections formed-or maintainedthrough the Internet (Bond et al., 2012; Ellison, Steinfield, \& Lampe, 2006; Gibson, Howard, \& Ward, 2000; Kavanaugh \& Patterson, 2001; Margetts, John, Escher, \& Reissfelder, 2011; Shah, Kwak, \& Holbert, 2001; Wellman, Haase, Witte, \& Hampton, 2001; Williams, 2006). Most of the research assessing the relationship between these new technologies and social capital assumes that the ties formed through online platforms carry a similar quantity and quality of resources (i.e., social capital) to relationships formed offline; however, this assumption has not been explicitly tested.

The aim of this article is twofold. First, to test the formation of the structural signatures of social capital online by analyzing online social networks. Here, we are interested in the relationship between social media and social capital formation, specifically how connections established via social media - in this case Twitter-lead to the formation of two specific forms of social capital, bridging and bonding capital. Our test here is explicitly structural. We examine the architecture of social networks, but not the content or quality of the links. As such, it marks a first and necessary test of whether there is evidence for online social capital. Second, we consider the relative importance of bridging and bonding capital. This is of special interest because one of the advantages of ICTs is to connect otherwise unconnected people, suggesting we might expect to see a different interplay between the two types of social capital than we see in face-to-face world interactions.

The distinction between bonding and bridging social capital as popularized by Putnam (2001) is one that is well-known and developed, but worth briefly rehearsing here. Bonding social capital exists in the strong ties occurring within, often homogeneous, groups-families, friendship circles, work teams, choirs, criminal gangs, and bowling clubs, for example. Bonding 
social capital not only acts as a social glue, building trust, and norms within groups but also potentially increasing intolerance and distrust of out-group members. Bridging social capital exists in the ties that link otherwise separate, often heterogeneous, groups - so, for example, individuals with ties to other groups, messengers, or more generically the notion of brokers. Bridging social capital allows different groups to share and exchange information, resources, and help coordinate action across diverse interests. Putnam emphasizes that these are not either/or categories, but that in wellfunctioning societies the two types or dimensions develop together.

Similar to other studies (Coleman, 1988; Shen, Monge, \& Williams, 2014), we use Burt's (2005) structural notion of social capital and two associated metrics, closure and brokerage, as indicators of bonding and bridging social capital, respectively. Closure refers to the level of connectedness between particular groups of members within a broader network and encourages the formation of trust and collaboration. Brokerage refers to the existence of structural holes within a network that are "bridged" by a particular member of the network. Brokerage permits the transmission of information across the entire network. Social capital, then, is comprised of the combination of these two elements, which interact over time. We use the observed values for closure and brokerage over time and compare them with different simulations based on theoretical network models to show how they compare with what we would expect offline. From this, we evaluate the existence and formation of social capital in online networks.

Using diverse-case criteria for case selection, we draw on Twitter data for three different events - the 2011 U.S. Occupy Movement, the U.K.-based IF Campaign organized by a coalition of U.K. non-governmental organizations (NGOs) around hunger and the 2013 G8 meeting, and the 2013 Chilean Presidential Election. We analyze the networks created by the transmission of information from these events to identify patterns of social capital formation within/among their structural features. Our data show that, contrary to Putnam, online networks show evidence of social capital and these networks exhibit higher levels of closure than what would be expected based on theoretical models. However, the presence of organizations and professional brokers is key to the formation of bridging social capital. Similar to traditional (offline) conditions, bridging social capital in online networks does not exist organically and requires the purposive efforts of network members to connect across different groups. Finally, the data show that interaction between closure and brokerage goes in the right direction, moving and growing together.

The article proceeds as follows. In the first section, we briefly review the theory of social capital and Putnam's skepticism of online social capital. We outline the two key indicators of online social capital used in this article, provide a brief review of the literature on network approaches to social interactions and on the role of organizations in collective action. Finally, we set out four research hypotheses derived from the theoretical discussion, and 
summarize the theoretical models that are used to test our hypotheses. The second section describes the methodology used to collect and analyze the data. The third section documents our results and provides a discussion of the main findings. The conclusion brings the article together and outlines fruitful directions for future research.

\section{Theory and Hypotheses Social Capital Online?}

According to Putnam (2001), computer-mediated communication makes online interactions unsuitable for the formation of social capital for four principal reasons. First, face-to-face interactions carry much more contextual information than online interactions due to the high degree of non-verbal communication that accompanies face-to-face communication. Second, faceto-face interactions can bring diverse people together, whereas online interactions take place among like-minded people, something he calls "cyberbalkanisation." Third, online interactions do not foster social capital because of a digital divide in access to the Internet, which allows for the interaction of members of the elite and not the public in general. Fourth, the Internet has more potential to become a form of entertainment rather than communication. We take up each of these differences in turn, and set out why, a priori, online interactions may indeed foster the development of social capital.

Putnam argues that online interactions are unable to foster social capital due to the absence of non-verbal cues and information, which form a large part of inter-personal communications. In the case of this first difference, we agree with Putnam: Offline interactions lack this fundamental feature. However, to our knowledge, no study has empirically shown the extent to which non-verbal communication is necessary for the formation of social capital or social trust and cooperation that flows from it. Second, with respect to cyberbalkanisation, recent research has shown (Brundidge \& Rice, 2009) that Facebook groups and profiles allow the emergence of political discussions among people who disagree, particularly through the connection of two persons who have a "friend" in common. Moreover, research by the Pew Research Internet project has shown that only $4 \%$ of social media users block, unfriend, or hide someone on the site because they disagreed with something the user posted about politics (Rainie \& Smith, 2012). In addition, research on Twitter has shown that, although people are more likely to interact with others who share the same views as they do during discussions on controversial topics, they are actively engaged with those with whom they disagree (Yardi \& boyd, 2010). These trends, however, have been observed mainly after the rise of social networking sites which, contrary to the general 
use of the Internet which Putnam had in mind in 2000, have specific affordances that promote socialization and interaction.

Rather than reinforce cyberbalkanisation, we argue that social media has the potential to facilitate discussion among different groups, particularly as online ties are not bound to their immediate communities creating the possibility of communication across traditional geographical boundaries. Online ties may facilitate communication among different individuals and groups because some of the initial barriers to communication in offline, faceto-face communication (gender, race/ethnicity, disability) are rendered less visible.

Although digital divide concerns persist, recent evidence shows a closing gap in access (Judge, Puckett, \& Bell, 2006). Moreover, offline interactions do not provide any insurance for discussions outside of elites. Other factors, such as geographical segregation, may be far more relevant for social integration than Internet access. Finally, although some scholars (Morozov, 2011) concur with Putnam's assessment of the Internet's greater potential for entertainment than communication, there is some evidence to show the Internet's communicative and mobilizing forces (Ward \& Gibson, 2009). This same assessment applies to offline organizations; joining organizations is not necessarily the same as interacting within those organizations.

In sum, we see no a priori reason(s) that social capital cannot exist online. But do differences in the form, features, or characteristics of online and offline interactions produce different forms of social capital? We think it is plausible. For example, online ties may be based more on the transmission of information than the personal characteristics of those interacting, such as geographical location, gender, ethnicity, or even more importantly, who they know. Online ties may not be as stable or durable as those created face-toface, because of the dynamic nature of the Internet. The level of engagement required to create a tie online might be lower than the engagement required offline, which might also have consequences for the type of resources they can mobilize. Finally, the categorization of weak and strong ties as proposed by Granovetter (1973) might not operate in the same way: The strength of an online tie may be better measured by the quantity of interactions and the frequency and quality of the information it transmits, rather than the personal characteristics of those making the connection.

Our aim in this article, however, is not to identify whether there are differences in online versus offline social capital, but to first establish evidence of social capital online. Like the bowling leagues that Putnam used to illustrate social capital offline, we argue that Twitter and Facebook discussions create social networks, operating under norms of trust and reciprocity, that are able to mobilize resources and information. In the next section, we examine the concepts of bonding and bridging social capital. Subsequently, we set out two theoretical models of social capital in online 
networks and drawing on these models, identify three hypotheses relating to the formation and structure of online networks.

\section{Observing Social Capital Online: Bridging and Bonding Social Capital}

The concept of social capital has traveled a long way since its original inception by Hanifan (1920), who described social capital as "those tangible substances that count for most in the daily lives of people" (p. 130). Since then, according to Webber (2008), there has been two streams of development of the concept: neo-capital and communitarian theories of social capital. Neo-capitalists (e.g., Bourdieu, 1986; Burt, 2005; Portes, 1998) are concerned with the relative advantage of a person within a group, that is, how the position of a person might bring them benefits in relation to the rest of the members of the network. This approach allows us to determine how the relationships we form are able to mobilize resources or, as Bourdieu would prefer, how much "capital" we can acquire through our social connections. In the case of communitarian approaches, as exemplified by Putnam, they look at the aggregate benefits of social connections. This approach is less concerned about the individual gains of participating in a network and more about the societal outcomes of them.

Within the communitarian approach, Putnam makes the distinction between bonding and bridging social capital. Bonding social capital exists in tight-knit networks that foster intra-group, strong ties. Putnam calls it a "sociological superglue," and explains that it is useful to build trust between the members of the group and increases the levels of solidarity. Bonding social capital might also be responsible for creating exclusion against those outside the group, which becomes the negative dimension of social capital. Bonding ties are the natural result of homophily (McPherson, Smith-Lovin, \& Cook, 2001), where people who share similar relevant characteristicssuch as geographical location, religion, ideology, among others - tend to group and work together. The other dimension of social capital, bridging ties, or the connections that people form outside their circles. This is similar to what Granovetter (1973) called "weak ties." Bridging social capital is responsible for coordinating action across different groups, and provides new information and resources to the more dense groups. Although both forms of social capital might be considered to be competing with one another, Putnam argues that they are not "either/or" categories: They operate in coordination and are different measurable dimensions of measure social capital. ${ }^{1}$

To examine evidence of social capital online, we take up the work of Burt (2005) who introduces two key indicators of social capital: closure and brokerage. The latter refers to the existence of a gap between two social groups, known as a structural hole. Brokerage takes place when two different groups are connected by a single node. Being a broker allows a person to have a better overview of the network and to become the only point of 
contact between two or more groups; hence, she can control the flow of information and resources through that network.

Social network structures consider the relationships built by people over time. These relationships can be dependent on contextual elements, such as work relations or, on a more personal level, friendship. Regardless of how we connect with others, the networks we build will have different structures. Some networks will be denser, with everyone in the group interacting with all of the other members (the basic definition of a cluster), whereas others will require someone to bridge different groups. The latter function of bridging is what we call "brokerage."

Like Putnam, Burt (2005) argues that brokerage works in cooperation with closure (Coleman, 1988). That is, to broker something between two groups, each one has to host cohesive ties among their members, or some degree of closure. Conceptually, closure can mean different things depending on the network. In a group of friends, closure might mean trust, intimacy, or frequency of contacts; whereas in a group of colleagues, closure might mean that they share work on the same project or the same working space. In that sense, what we understand by closure may change depending on the type of social network we are observing. The important thing to consider is that closure allows a network to build trust among its members, by providing a safe environment for social relations. Hence, closure is essential for the creation of resources and information within a group, which in turn can be mobilized by a broker to another group.

A useful example of closure provided in the literature (Christakis \& Fowler, 2011) is the dynamics of military companies. A company of 100 soldiers is usually composed of 10 groups of 10 soldiers each. It is important for the efficiency of the whole company that each group of 10 becomes very close and that everyone in the groups knows each other. But within group closure is not enough for the emergence of social capital. It is also important that each group has ties with members of the other groups, that is, what Granovetter (1973) would call "weak ties," to transmit information and resources. Thus, it is the interplay of closure and brokerage that provides the company with an optimal level of social capital.

As with the conjunction between closure and brokerage, the important element of social capital refers to a collective behavior based on trust and reciprocity. Putnam claims that the benefits of participating in voluntary associations are not only individual but also bring positive outcomes at a societal level. His distinction between bridging and bonding social capital takes the brokerage and closure discussion to an aggregate level by arguing that intra-group ties build trust and mobilize diverse resources.

From a conceptual point of view, Burt's concepts of closure and brokerage offer a useful way of bringing the neo-capital and communitarian approaches to social capital together. Burt provides a clear conceptual definition that not only fits most of the elements of Putnam's categories but also provides a path for 
rationalizing them. Closure operates in the same way as bonding social capital, favoring intra-group ties, fostering the formation of trust and building dense communities. However, brokerage provides a fresh flow of new information to the network, allows for the mobilization of different resources, and uses the trust formed by closure to act as a tool for collective action. Our approach here has been to demonstrate the similarity of Putnam's bonding and bridging capital and Burt's closure and brokerage concepts. Thus, we employ Burt's measures as indicators of bonding and bridging capital at the aggregate level. A explanation of the differences between the approaches can be found in Table 1.

Finally, the decision to use these concepts (brokerage and closure) as measures for bonding and bridging social capital stems from the need to provide better indicators for these concepts. Currently, measures of social capital are analyzed either using social network analysis or survey instruments such as the name generator (McCallister \& Fischer, 1978), the position generator (Lin, 2008), and, more recently, the resource generator (Van Der Gaag \& Snijders, 2005). Some researchers (Ellison, Steinfield, \& Lampe, 2011; Kwon, D’Angelo, \& McLeod, 2013) have also used survey instruments to assess the presence of bonding and bridging social capital in online platforms. In our view, this kind of exercise introduces two sources of bias. On one hand, the use of self-reported data may lead to a misrepresentation of the actual networks. On the other hand, this type of data only allows for the analysis of ego-networks (i.e., the connections of a single node), and thus excludes the possibility of observing directly the interplay among different social groups. This concern has been shared by Appel et al. (2014), who emphasize the lack of validity of most survey instruments used to measure social capital in ICTs.

Table 1. Distinction Between Neo-Capital and Communitarian Approaches in Terms of the Type of Ties Within a Network.

\begin{tabular}{llll}
\hline & \multicolumn{1}{c}{ Focus } & Intra-group ties & Inter-group ties \\
\hline $\begin{array}{l}\text { Neo-capitalist } \\
\text { approach }\end{array}$ & $\begin{array}{l}\text { Individual advantage Closure } \\
\text { of a person in a } \\
\text { network }\end{array}$ & Brokerage \\
$\begin{array}{l}\text { Communitarian } \\
\text { approach }\end{array}$ & $\begin{array}{l}\text { Aggregate benefits } \\
\text { of networks }\end{array}$ & $\begin{array}{c}\text { Bonding social } \\
\text { capital }\end{array}$ & $\begin{array}{c}\text { Bridging social } \\
\text { capital }\end{array}$ \\
\hline
\end{tabular}

In their recent article, Gibson and McAllister (2013) define bridging social capital as interacting with people from different ethnic backgrounds, ages, or countries and bonding social capital as interacting with family, close friends, or people with shared hobbies, religious beliefs, or political views. Their work uses survey-based, self-reported measures of social capital or, in other words, use ego-centric measures derived from the respondent's view of how he or she connects to the rest of the world. They show that only bonding social capital is significantly and positively related to political participation; 
bridging social capital is not correlated with political activities. We argue that the use of observed networks provides an unbiased opportunity for analyzing bonding and bridging social capital.

We are interested in seeing whether our approach complements Gibson and McAllister's (2013) findings, especially because we use actual networkbased measures of social capital, which they do not. Our measure is different and is derived empirically from the structure of the network. For us, a bridging tie is literally one that bridges between groups and bonding ties are within group links. This means that we do not have to rely on people's perceptions of whether the Internet allows them to form in-group or outgroup ties; we calculate this from the actual network of ties itself. What is of interest then is the extent to which our results complement theirs.

\section{The Role of Organizations in the Investigation of Online Social Capital}

Inspired by the classic work of de Tocqueville (2006) on "Democracy in America," Putnam (2001) places particular emphasis on the benefits of organizational membership for the creation of social capital. According to Putnam, organizational involvement can have important benefits for the community (and for democracy in general) by providing organization members with the necessary competencies for participation in public life, fostering the creation of social capital. Most crucially, organizational involvement has been shown to be an important antecedent not only of civic engagement and involvement in collective action (McCarthy \& Zald, 1977) but also for the maintenance and enhancement of strong ties-especially among activist groups (McAdam, 1990).

Recently, the extent to which organizations are required for collective action has been questioned. Bimber, Flanagin, and Stohl (2012) argue that the presence of "organization-less organizing," such as the protests against the WTO meeting in Seattle in 1999, is becoming increasingly common. That said, they do not ignore the role of formal organizations, noting how some organizations have been thriving by adapting to possibilities brought by new technologies. They argue that organizations are flexible, adaptive, and adopt new technologies over time. The key difference is that organizations are no longer both a necessary and sufficient condition for collective action, such as classical studies suggest (Olson, 1965).

In line with that argument, some researchers (Bennett \& Segerberg, 2013) propose a new way to conceptualize collective action, which emphasizes the role of the connections among people, rather than the fact that they come together as a collective. In their view, collective action efforts can be framed in three different ways: (a) organizationally brokered collective action, which contains "coalitions of heavily brokered relations among organizations" (Bennett \& Segerberg, 2013, p. 13), namely, the role that traditional theory 
assigns to organizations; (b) organizationally enabled connective action, which refers to the presence of loosely tied organizations that allow for people to personalize their engagement; and (c) crowd-enabled connective action, where individuals connect by themselves using digital media platforms, and organizations play a peripheral role, if any at all. There is an important distinction to be drawn between the thinner view of connective action (Bennett \& Segerberg, 2013) and the thicker view of social capital. Connective action is merely transactional. It allows people to organize. Social capital is transformational. It results in social externalities, thickening the social glue of trust and shared norms. To be clear, our approach here is to examine the social structure of connective action, which may or may not result in lasting social capital. We do not examine the content of online ties, which would allow us to assess the quality of the connections. We argue that our structural approach is a necessary, but not sufficient, first step to in assessing whether there is any evidence for online social capital.

These changes pose an intriguing question about the role social media can play in the generation of social capital in the context of different organizational settings. Indeed, based on Bennett and Segerberg's (2013) typology which distinguishes between different degrees of organizational involvement, we hypothesize that the level of brokerage and closure within networks of collective action should differ depending on the involvement of formal organizations within them. When their presence is central to the collective efforts, they play a role in moving information and resources across the networks. Thus, their absence leaves an open question on whether bridging connections could emerge without them.

\section{Hypotheses and Theoretical Models}

Drawing on the closure and brokerage concepts set out above, we test four hypotheses with regard to the structural features of online networks and how they relate to the formation of social capital. We analyze the levels of closure and brokerage from a set of online networks and compare them with both random simulations and the most common theoretical models used to explain the formation of social networks. We use the outcome from that exercise to test our four hypotheses.

The first hypothesis is a baseline measure that aims to test whether the levels of brokerage and closure we observe online are the product of purposive efforts to interact, or if they are indistinguishable from any other random network with the same number of nodes and ties. Hence, we test the observed values we get from the online networks against random graphs. Although it is likely that they will differ, testing this hypothesis allows us to move forward and make an informed decision on whether the networks present a basic level of systematic social connections. 
Hypothesis 1 (H1): The levels of bridging and bonding social capital formed through online interactions are significantly different than random.

To construct the random graphs, we use the first variant of the ErdosRenyi (ER) model, $G(n, M)$, which assumes that a graph is randomly selected from all the different possibilities of graphs with a fixed number of nodes $n$ and vertices $M$. Each node in the graph, then, has the same probability of being connected with any other node from the same graph. We assigned the fixed number of nodes and edges according to the observed information. For this hypothesis, we run two-sample $t$ tests to compare the difference in means between the observed and the random networks.

Hypothesis 2 (H2): The networks formed through online interactions are, on average, less dense and weaker than those generated by the theoretical models.

This hypothesis tests Putnam's argument that online ties are not able to produce social capital as face-to-face ties are. As building counterfactuals to online networks is an almost impossible task, we test the observed values we get from the online networks against two theoretical models that are commonly used to explain social networks formation: the Barabasi-Albert model and the Watts-Strogatz model.

The Barabasi-Albert (BA) model is based on the notion of preferential attachment. That is, it starts an initial random graph and creates new nodes, one at a time. The main assumption is that nodes are more likely to connect with other nodes that are better connected. The aim of this model is to account for the level of influence of certain nodes in the network. Those who have more links will attract more to connect with them. Formally, the model starts with a network with $m_{0}$ nodes. Each new node is connected to $m \leq m_{0}$ existing nodes with a probability that is proportional to the number of links that the existing nodes already have. The probability $p_{i}$ that the new node is connected to node $i$ is

$$
p_{i}=\frac{k_{i}}{\sum j k_{j}},
$$

where $k_{i}$ is the degree of node $i$ and the sum is made over all pre-existing nodes $j$. Heavily linked nodes tend to quickly accumulate even more links, whereas nodes with only a few links are unlikely to be chosen as the destination for a new link. The new nodes have a "preference" to attach themselves to the already heavily linked nodes.

Finally, the WS model overcomes two main criticisms of the ER models. First, it accounts for the formation of triadic closure in a network - that is, if we have three nodes $A, B$, and $C$, where there are strong ties between $A$ and 
$C$, and $A$ and $B$, it is very likely that there will be a weak tie between $B$ and $C$. Second, the degree distribution of ER models form a Poisson distribution, because it does not assume that highly connected nodes can link each other with higher likelihood. WS starts with a fixed number of nodes $N$ connected with degree $K$ (which needs to be an integer), each one connected in a circular lattice with its neighbors. Then, the model rewires each one of the edges of a node $i$ with another node $k$ with a probability $\beta$ that each node will be selected. No self-loops or duplicated edges are allowed. The main advantage of this model is that it accounts for the small-world effect (i.e., even if most nodes are not neighbors to each other, they can be easily connected from every other with a small number of steps) by producing higher levels of clustering coefficient than the BA model. The BA model, however, produces more realistic degree distributions.

The models use the information from the observed networks - such as the number of edges and vertices, or the average degree - to build their own networks. For each model (including the random graphs), we simulated a 100 different random iterations of the graphs and calculated their average values for closure and brokerage. We used the observed graphs as a reference for the number of nodes and edges required for the calculation of the models. For $\mathrm{H} 2$, we compared the observed values against all the models.

Based on Putnam's argument that online interactions are unsuitable for the formation of social capital, our expectation is for the observed clustering coefficient to be lower and the network constraint to be higher than in the theoretical models. In particular, we might expect cyberbalkanisation and the digital divide to restrict the formation of social capital in the three online networks we consider.

We might expect tweets about the Occupy movement to be largely restricted to like-minded people, particularly those directly involved in it given the nature of protest movements. The potential for cyberbalkanisation is particularly high for the IF Campaign. Within the international development literature, it has been noted that levels of public engagement (in the United Kingdom) with issues of global poverty and development are low and declining (see Darnton \& Kirk, 2011). As such, there is a high possibility that tweets about the NGOorganized IF campaign are likely to be restricted to those already involved with these NGOs, rather than across the public more generally. Similarly, we would expect tweets about the Chilean Presidential election to take place among those that are already more politically engaged, and may be restricted to those with similar political views.

In the case of the IF campaign and the Chilean Presidential elections, it is also important to note that targeting social network sites are part of the campaign strategy used by organizers. As such, much of the Twitter activity in these two networks is likely to be driven by organizations and professional brokers, restricting network formation to being concentrated around these brokers. As such, we would expect online network for the IF campaign to be 
centered around the NGOs and NGO staff members, rather than between members of the general public. The same would apply to the online network for the Chilean election campaign, which is likely to be constrained around political parties and activists.

Hypothesis 3 (H3): In online networks, bonding and bridging social capital operate in coordination, strengthening each other.

To test this hypothesis, we used the observed values for each event and calculate their correlation coefficient, using both parametric (Pearson's $R$ ) and non-parametric (Kendall's $\tau$ ) tests. We expect to observe positive covariation between brokerage and closure. As Putnam explains, both forms of social capital-bridging and bonding-should operate in conjunction to produce a positive societal outcome. In empirical terms, that requires that the presence of both should be related, but not working against each other.

Hypothesis 4 (H4): In cases where organizations play a relevant role, we should expect higher levels of bridging social capital in relation to the different theoretical models.

Bennett and Segerberg (2013) have provided a solid theoretical framework about how digital networking mechanisms embedded in the layers of networks can provide the means of coordinating actions. There are two important points here that are relevant to our analysis. First, communication within such networks can be thought of as an act of organization in technology-enabled networks. Second, a signature feature of this type of communication is the increased personalization of action online; that is, a form of engagement in which new media are used to carry personal stories and other content across networks. However, not all networks are the same; it is indeed conceivable that different content is communicated - in a different way and with different organizational signatures - across a network about an electoral campaign, a spontaneously organized demonstration against bankers, and a well-organized protest march as part of an ongoing humanitarian campaign.

Following Bennett and Segerberg's typology, and this general line of argument about digitally networked action, we argue that social capital can be formed through technology-enabled interactions and observed not only through analyzing tweets to detect personalized action frames but also at the structural level. The receipt, adaptation, and communication of personalized action frames that can be widely shared across different networks, and subsequently enable discussion and further involvement with a particular campaign/cause, are likely to result in the development of social capital. However, depending on the type of network examined, we expect that different types of social capital development will be more prominent in some 
networks than others. In this particular case, we expect to find more bridging social capital in networks where organizations play a more central role.

The expected outcomes for each hypothesis are shown in Table 2.

\section{Data and Method}

We draw on Twitter data to test the four hypotheses set out above across three different cases: the Occupy Movement in the United States (2011), the

Table 2. Hypotheses and Expected Outcomes.

\begin{tabular}{|c|c|c|}
\hline Hypotheses & Indicator & Expected outcome \\
\hline $\begin{array}{l}\mathrm{H} 1: \text { Observed networks } \\
\text { are different than } \\
\text { random }\end{array}$ & $\begin{array}{l}\text { Average local clustering } \\
\text { coefficient and network } \\
\text { constraint ( } t \text { tests) }\end{array}$ & $\neq$ \\
\hline $\begin{array}{l}\mathrm{H} 2 \text { : Observed bridging } \\
\text { and bonding social } \\
\text { capital are lower than } \\
\text { the theoretical models }\end{array}$ & $\begin{array}{l}\text { Average local clustering } \\
\text { coefficient and network } \\
\text { constraint }\end{array}$ & $\begin{array}{l}\text { <clustering coefficient, } \\
\text { >network constraint }\end{array}$ \\
\hline $\begin{array}{l}\mathrm{H} 3 \text { : Closure and } \\
\text { brokerage work in } \\
\text { cooperation }\end{array}$ & $\begin{array}{l}\text { Correlation coefficient } \\
\text { (Pearson and Kendall) }\end{array}$ & + \\
\hline $\begin{array}{l}\text { H4: Bridging social capit } \\
\text { is higher in } \\
\text { organizations-led } \\
\text { networks }\end{array}$ & $\begin{array}{l}\text { Average local clustering } \\
\text { coefficient }\end{array}$ & $\begin{array}{l}\text { >in organization-led } \\
\text { networks in relation to } \\
\text { the theoretical models, } \\
\text { and compared with the } \\
\text { other cases }\end{array}$ \\
\hline
\end{tabular}

Note. $\mathrm{H} 1=$ Hypothesis $1 ; \mathrm{H} 2=$ Hypothesis $2 ; \mathrm{H} 3=$ Hypothesis $3 ; \mathrm{H} 4=$ Hypothesis 4.

U.K. Enough Food for Everyone "IF" global hunger campaign organized by U.K.-based NGOs to coincide with the U.K. G8 meeting (2013) and the Chilean presidential elections (2013). The three cases have been chosen using a "diverse-case" selection criteria around organizational presence. This approach is a departure from previous analyses of Twitter data which have focused on events similar in nature: for example, the use of Twitter for protests (González-Bailón, Borge-Holthoefer, Rivero, \& Moreno, 2011), political campaigns (Vaccari et al., 2013), charitable campaigns (Clements, 2011), or using the entire population of tweets for a certain time period (Morstatter, Pfeffer, Liu, \& Carley, 2013). Drawing on Bennett and Segerberg's (2013) typology of collective action, the cases (networks) represent one of three observed types: (a) crowd-enabled connective action network, (b) organizationally brokered connective action network, and (c) organizationally enabled connective action network. Variation across the cases allows us to test our hypotheses across both spatial and temporal 
domains, and because the observed cases represent varying degrees of connective action, we can generalize findings here to the wider population.

- OWS: Crowd-enabled connective action network. Previous research (Conover, Ferrara, Menczer, \& Flammini, 2013; Fábrega \& Sajuria, 2014) has shown that this case is a prime example of this type of political activism. OWS activists showed reluctance to allow formal organizations to play a key role in the movement. Moreover, they emphasized the role of technology as the means for connection, rather than membership to organizations. This was to be expected from a public that was openly suspicious of processes that require delegation and, hence, handing over individual empowerment to others; technology-enabled networks as a means of connection provided for them a more neutral and self-empowering affiliation (Tufekci, 2014).

- IF Campaign: Organizationally enabled connective action network. The IF campaign was the first campaign to be launched on Twitter by an umbrella group representing more than 200 NGOs. IF organizers continuously updated their hashtags and personalized action frames based on central events, fulfills all the requirement for an organizationally enabled connective action network.

- Chilean election: Organizationally brokered collective action network. Like in most traditional political campaigns, the Chilean election had a group of political parties from each coalition seeking to mobilize people on Twitter toward their candidates. Basically, they were organizations looking to magnify their support and membership.

The Occupy movement started in October 2011, after a group of protesters decided to occupy Zucotti Park in New York. Their primary aim was to demonstrate against high levels of inequality and the monetary system maintaining inequality. From that initial occupation several occupations took place across the United States and beyond. The data for Occupy were obtained through the Occupy Research project (www.occupyresearch.net), a collaborative network of researchers interested in the Occupy movement. They were gathered by R-Shief (www.R-shief.org) using the Twitter Streaming API for a period of 13 weeks, following the onset of the movement on October 2011. The data contain tweets using the different hashtags related to the movement, in particular, those referring to cities where occupations took place. We focus on all tweets using the "official" hashtag of the movement (\#ows; $N=4,352,071$ tweets). The emphasis on hashtags is not without question. Focusing on them allows us to observe only those who had a minimal level of involvement in the discussions about the Occupy movement. Whereas the use of hashtags relates to a particular group of users, those who use them are those who we especially target. 
The IF campaign was a coalition of more than 200 U.K. NGOs seeking to put pressure on the G8 governments meeting in the United Kingdom in the summer of 2013. The campaign's focus was on global hunger and sought to get the G8 leaders to make commitments to tackle four underlying drivers of malnutrition - insufficient aid and investment, the problem of land grabs, the failure to tax multinational companies, and a lack of transparency around deals and investment. The data from the IF Campaign were gathered using DiscoverText (www.discovertext.com), from January 23 to October 16, the official start and end dates of the campaign, using the live feed API. We collected tweets that contained the official hashtags used by the campaign (e.g., \#IF, \#IFCampaign, \#BigIF, \#BigIFLondon, \#BigIFBelfast). Given the large number of coalition members, we decided to collect tweets using the hashtags of campaign as a whole rather than the many organizational twitter handles. We anticipated that this would allow us to gather all campaignrelated tweeting, both from the official campaign, member organizations, and discussion by the public. The official hashtags were provided in advance by the campaign. Because the main hashtag - \#IF - was widely used for noncampaign tweeting we unavoidably collected a high number of non-campaign related tweets. As such the data were cleaned using DiscoverText's built in machine classifier (a naïve Bayesian classifier) resulting in a total of 101,842 units.

The data for the Chilean election were obtained through the Analitic platform (www.analitic.cl), which uses the Twitter "Gardenhose" API. We collected the tweets related to the two main candidates for this election, Michelle Bachelet and Evelyn Matthei. The tweets were selected based on the use of the name of the candidates, either as a mention, in hashtags containing the names, or their names without an "@" at the beginning. This approach, unlike using hashtags, has been shown to be more appropriate for the analysis of tweets during election campaigns (DiGrazia, McKelvey, Bollen, \& Rojas, 2013). The time period spanned from 7 weeks before the run-off election until December 17, 2013, which covered the entire legal campaign period for both rounds ( $n=1,556,109$ tweets).

The data sets $^{2}$ were filtered, leaving the username of the sender, the date of the tweet, and any corresponding text. Each data set was then divided into weekly static networks, creating a list of all usernames contained within the text of the tweets. An edge list was created using the username of the sender, and assigning a directed edge to any other usernames mentioned in their tweets. To account for more stable relationships among users, we filtered out any edges (ties) with a degree less than two. Descriptive statistics for each data set is presented in Table 3 .

\section{Measures}


To assess the level of closure for each network, we used the average local clustering coefficient metric. This value, for each weekly network, was calculated using an algorithm (Watts \& Strogatz, 1998) that determines how

Table 3. Descriptive Statistics.

\begin{tabular}{lcccccc}
\hline & \multicolumn{2}{c}{ IF campaign } & \multicolumn{2}{c}{ OWS } & \multicolumn{2}{c}{ Chilean election } \\
\cline { 2 - 7 } Week & Vertices & Edges & Vertices & Edges & Vertices & Edges \\
\hline 1 & 3,334 & 478 & 40,223 & 28,480 & 94,768 & 30,682 \\
2 & 3,333 & 478 & 69,799 & 86,308 & 45,156 & 9,606 \\
3 & 1,660 & 220 & 42,747 & 23,483 & 87,220 & 16,445 \\
4 & 1,514 & 266 & 47,067 & 36,721 & 83,333 & 13,607 \\
5 & 1,221 & 162 & 60,323 & 71,216 & 34,261 & 6,372 \\
6 & 1,363 & 118 & 42,168 & 28,564 & 37,450 & 9,287 \\
7 & 2,637 & 284 & 30,793 & 16,289 & 68,499 & 18,115 \\
8 & 3,617 & 711 & 45,118 & 35,314 & & \\
9 & 2,176 & 239 & 63,185 & 86,258 & & \\
10 & 380 & 31 & 53,687 & 46,380 & & \\
11 & 932 & 70 & 47,361 & 36,027 & & \\
12 & 932 & 70 & 41,153 & 31,683 & & \\
13 & 1,028 & 124 & 25,874 & 11,585 & & \\
14 & 1,946 & 111 & & & & \\
15 & 1,053 & 116 & & & & \\
16 & 2,469 & 255 & & & & \\
17 & 1,677 & 523 & & & & \\
18 & 1,504 & 190 & & & & \\
19 & 4,146 & 728 & & & & \\
20 & 12,532 & 3,481 & & & & \\
21 & 4,813 & 1,135 & & & & \\
22 & 347 & 7 & & & & \\
\hline
\end{tabular}

close a node and its neighbors are to becoming a clique (a graph of fully connected nodes). Any graph $G=(V, E)$ formally consists of a set of vertices $V$ and a set of edges $E$ between them. An edge $e_{i j}$ connects vertex $v_{i}$ with vertex $v_{j}$. The neighborhood $N_{i}$ for a vertex $v_{i}$ is defined as its immediately connected neighbors as follows:

$$
N_{i}=\left\{v_{j}: e_{i j} \in E \wedge e_{j i} \in E\right\} .
$$

Let $k_{i}$ be the number of vertices, $\left|N_{i}\right|$, in the neighborhood, $N_{i}$, of a vertex. The local clustering coefficient $T_{i}$ for a vertex $v_{i}$ is then given by the proportion of links between the vertices within its neighborhood divided by the number of links that could possibly exist between them. For a directed graph, $e_{i j}$ is distinct from $e_{j i}$, and therefore for each neighborhood $N_{i}$ there are $k_{i}\left(k_{i}-1\right)$ links that could exist among the vertices within the neighborhood. Thus, the local clustering coefficient for directed graphs is given as, 


$$
T_{i}=\frac{\left|\left\{e_{j k}: v_{j}, v_{k} \in N_{i}, e_{j k} \in E\right\}\right|}{k_{i}\left(k_{i}-1\right)} .
$$

From this, we can calculate the average local clustering coefficient for all the vertices $n$ :

$$
\bar{T}=\frac{1}{n} \sum_{i=1}^{n} T_{i} .
$$

To calculate brokerage, we use Burt's (2005) Network Constraint Index which measures the lack of structural holes within a network. A structural hole exists where two groups in a network are unconnected. The ability to bridge a structural hole bestows power on an actor in a network because they can valuably control and broker the flow of information between the two groups. Constraint is defined as a situation where an actor does not have access to structural holes and so cannot benefit from exploiting a brokerage position. To get at this, Burt's measure focuses on how much the connections of node $i$ are concentrated in a single group of interconnected nodes, which in turn constrain $i$ 's ability to bridge across groups. This can be expressed as follows:

$$
C_{i}=\Sigma c_{i j}, i \neq j,
$$

where $C_{i}$ is the network constraint of $i$, and $c_{i j}$ refers to the dependence of $i$ on $j$,

$$
c_{i j}=\left(p_{i j}+\Sigma_{q} p_{i q} p_{q j}\right)^{2}, i \neq q \neq j,
$$

where $p_{i j}$ is the proportion of $i$ 's connections are invested in node $j$, so that $p_{i j}=z_{i j} / \Sigma_{q} z_{i q}$. Here, $z_{i j}$ is the measure of the strength of the association between $i$ and $j$, so the constraint of each individual level goes from 0 to 1 , depending on whether $i$ 's connections are invested in $j$.

Network constraint, as the sum of $c_{i j}$ across all $i$ 's connections, provides a measure on how much $i$ is limited by their own network in accessing new information coming from other groups (which needs to cross over a structural hole). Therefore, constraint will vary according to the size, hierarchy, and density of i's network. Constraint is higher when someone has fewer connections that are highly interconnected to each other. The level of interconnection can happen directly $\left(p_{i j}\right)$ between the members of $i$ 's networkin a dense network - or indirectly $\left(\Sigma_{q} p_{i q} p_{q j}\right)$ through a single node-like in a hierarchical network. Our networks, in particular, do not present a theoretical hierarchy, due to the horizontal nature of the interactions. Unlike work environments - the original setting for Burt's work-our cases are less likely to present hierarchical structures. To calculate brokerage, we average the nodespecific constraint $C_{i}$ across the networks to obtain $\bar{C}$.

Both metrics-clustering coefficient and network constraint-are good indicators of closure and brokerage. In summary, a higher value on clustering coefficient indicates a higher level closure, a lower network constraint values 
indicate higher levels of brokerage. Previous findings (Burt, 2000, 2005) show that both measures are associated with higher levels of individual social capital.

\section{Results and Discussion}

Figures 1 and 2 show the development of closure and brokerage over time for each network. Figure 1 shows closure, week by week, in comparison with the different theoretical models. The data show that the levels of closure are higher (slightly) for the observed networks than for any of the models, in each of the three data sets. That is, given the number of edges, vertices, and the average degree of the networks, none of the simulated models are able to create higher levels of closure. This finding partially supports $\mathrm{H} 2$, by showing that online networks seem to be more efficient in forming small, denser communities than what theory would expect. This suggests that online networks are able to produce bonding social capital and their levels of closure are not explained simply by random allocation of nodes and ties.

In the case of network constraint (Figure 1), the support for $\mathrm{H} 2$ is also only partial. None of the observed networks are able to produce higher levels of brokerage than the theoretical models. Moreover, in the case of Occupy, the levels of brokerage are even lower than the random graphs. In the case of the IF campaign and the Chilean election, brokerage was consistently above the random models, which shows that the connections across structural holes present in these networks are higher than we would expect on any random network.

Two points warrant further consideration. First, the presence of brokerage opportunities is lower in online networks than the theoretical expectations, and the ability of members' of the networks to connect groups across structural holes is less efficient that what we would expect. Second, the difference between the OWS movement and the other cases raises questions about the nature of the events and whether differences in the presence of organizations may explain the differential findings with respect to brokerage. On top of what we have anticipated in $\mathrm{H} 4$, one of the potential reasons for this difference is that the Occupy case is less constrained in two particular aspects: geography and scope of issues. As has been described by the literature (Conover, Davis, et al., 2013), the Occupy Movement reached places beyond the United States, but was highly concentrated on local events in each city. Moreover, the issues raised by the demonstrators ranged from the (rather vague) claim for more equality, to more concrete topics (e.g., the change in the financial system) depending on the place of the occupation (Castells, 2012; Chomsky, 2012). For these reasons, we performed a second set of analyses on the Occupy case. 


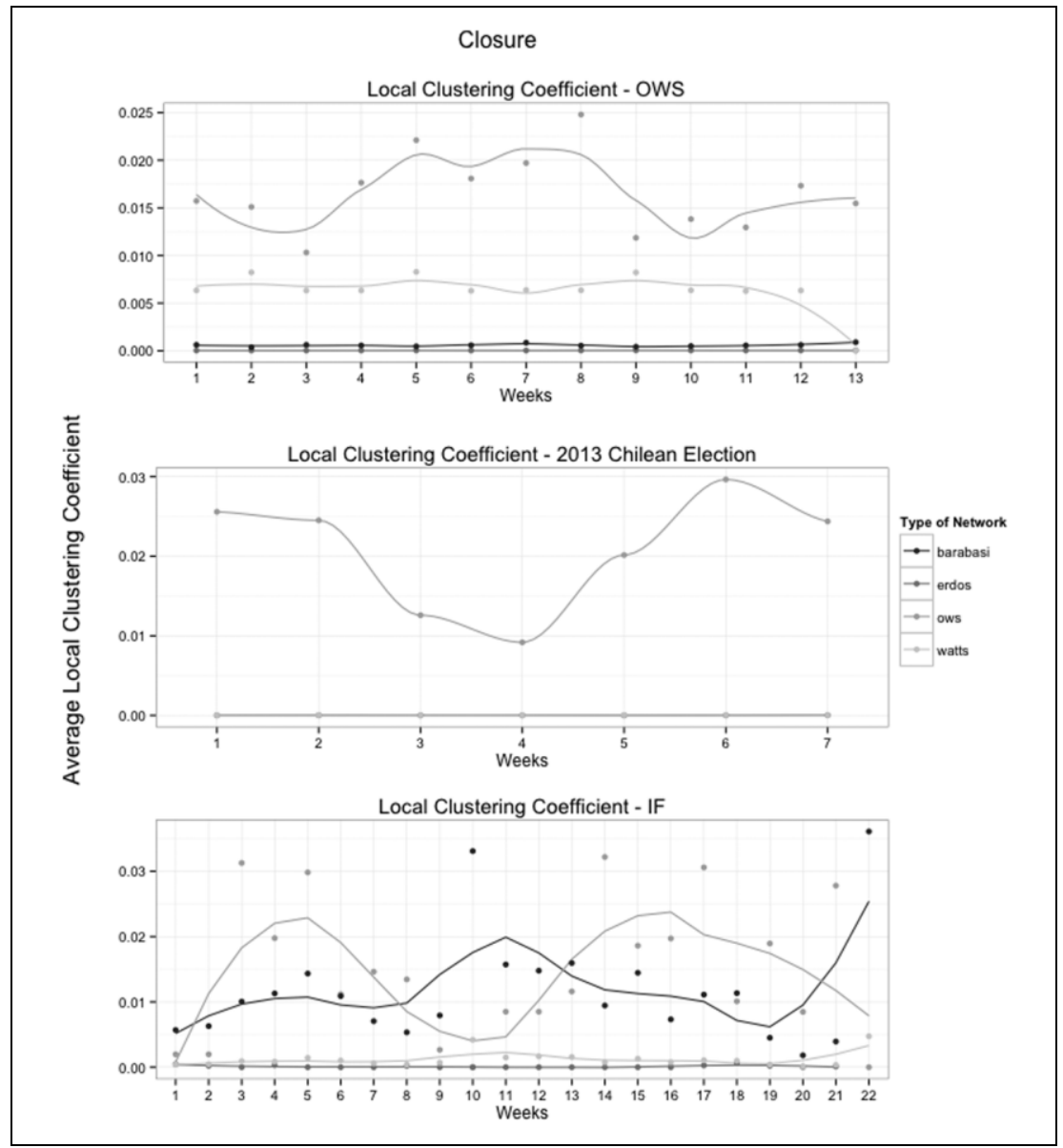

Figure 1. Closure for the three networks.

Note. The lines are fitted using a local polynomial regression fitting, with $\alpha=.5$.

Using the data from two cities in the United States-Oakland and Boston - we calculated the levels of brokerage for each network and compared it with the simulated networks (using hashtags \#OccupyOakland and \#OccupyBoston, respectively). The aim of this analysis is to establish whether the trend of low brokerage is something inherent to the Occupy movement, or was simply less evident in the wider, (inter)national network given its diffuse set of issue concerns and sizable geographic constituency. We expect that the Oakland and Boston chapters of Occupy will show higher levels of brokerage (in relative terms) than the broad-based Occupy/\#OWS. 


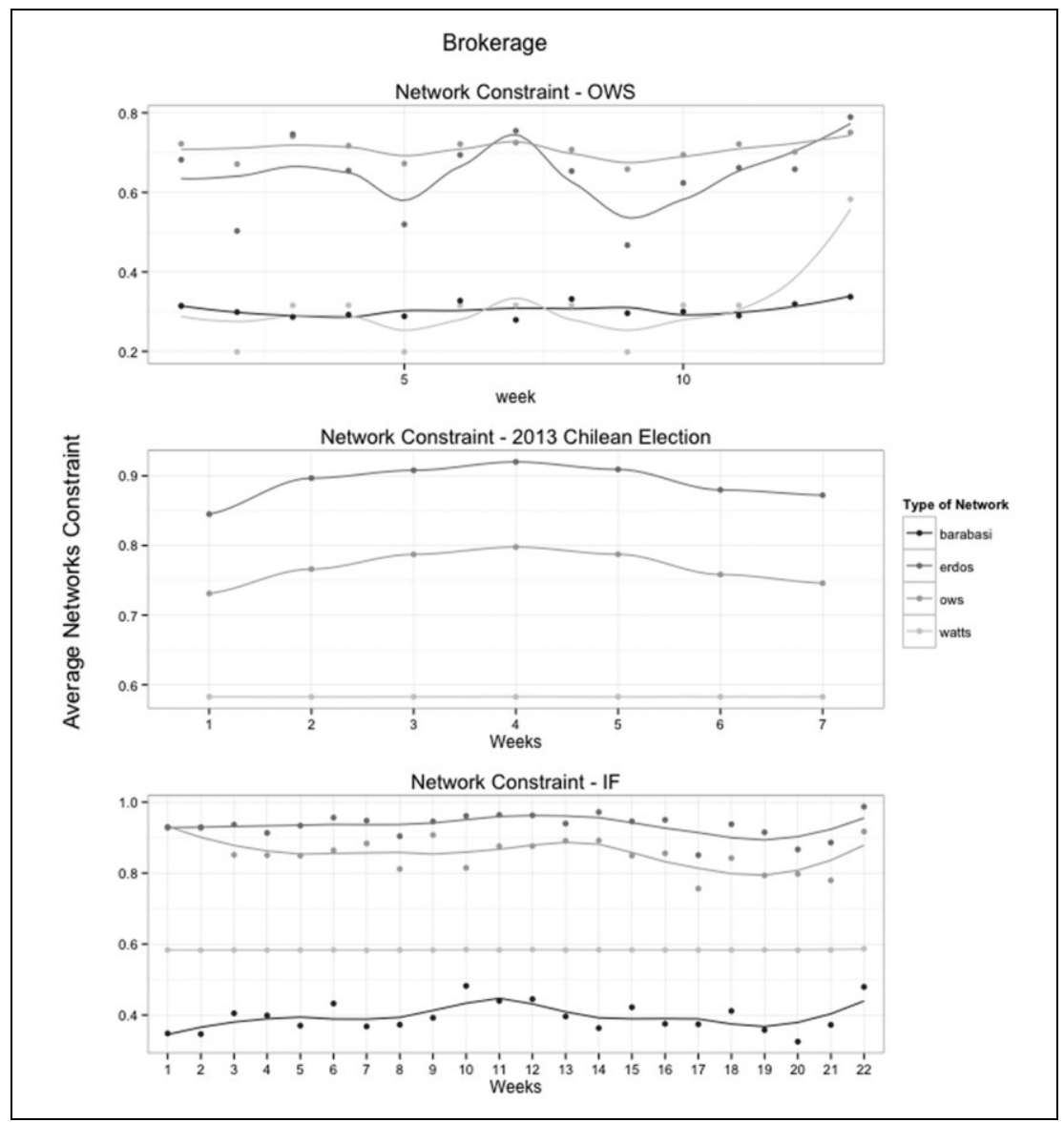

Figure 2. Brokerage for the three networks.

Note. The lines are fitted using a local polynomial regression fitting, with $\alpha=0.5$.

Figure 3 shows the results for both networks. In the case of Boston, the trend was exactly the same as in the OWS networks: brokerage was lower than any of the theoretical models, including the random simulations. The difference is statistically significant and is consistent with the results from the general Occupy movement. The case of Oakland, however, shows more disparate results. The results remain different at a $p<.05$ level, which means that the observed values differ significantly from the simulations, however, the results show no clear trend over time. The observed networks show, at points, even higher levels of brokerage than most of the models (with the exception of WS), and during other weeks the brokerage is lower than the simulations. 


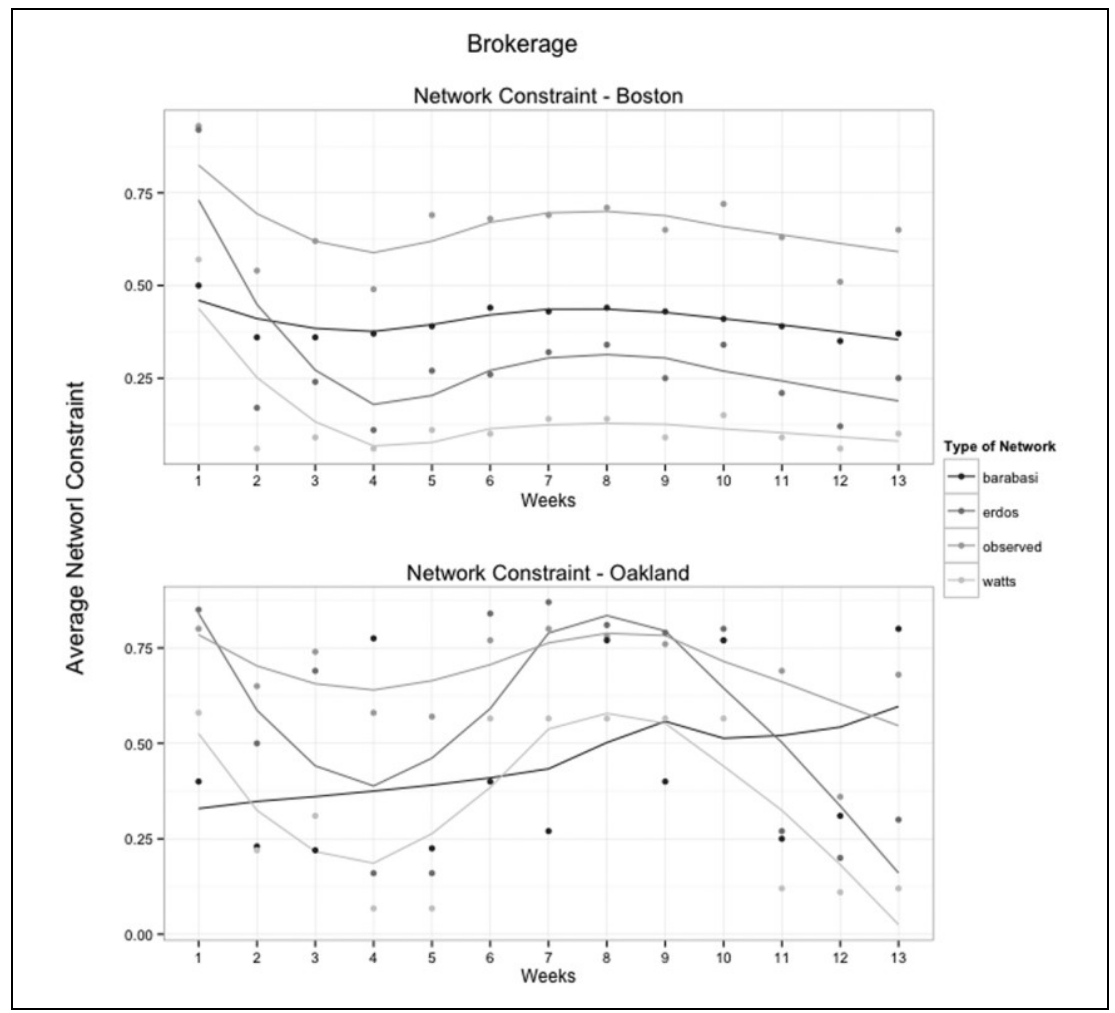

Figure 3. Brokerage for Oakland and Boston.

Note. The lines are fitted using a local polynomial regression fitting, with $\alpha=.5$.

Looking at the results more closely, the weeks where brokerage is lower are those where the number of edges is higher. This is consistent with the idea that more ties within a limited network will eventually work against the existence of structural holes. Nevertheless, this does not answer the question of why the levels of brokerage are consistently lower in the other Occupy data sets, but not in this one. ${ }^{3}$ After accounting for geographical conditions, we believe that these results support $\mathrm{H} 4$, that is, that organizations play a key role in fostering brokerage in collective action networks.

In summary, we find only partial support for $\mathrm{H} 2$ with respect to closure: Online networks are able to foster the creation of tight, small groups within the network and do so better than what would be predicted if random. With respect to brokerage, the story is twofold. On one hand, the IF campaign and the Chilean election networks show similar results (as in closure), whereas the OWS networks do not show any more brokerage than what we might expect at random. In the case of the Occupy, this result was tested with smaller groups within the Occupy movement, but with disparate results. 
Our results showing differences in brokerage between OWS and the other two cases warrants further consideration. Beyond the more technical inferences about the differing results, we argue that OWS may differ substantively from the other two cases. Both the Chilean election and the IF campaign are highly organized, well-funded, and tightly focused events. Given that the main aim of campaign communications, Twitter or otherwise, is to influence attitudes, preferences, or vote choice, we would expect to see a higher number of organizations hiring "professional brokers," that is, people whose main job is to connect the different supporters of a given candidate, transmit information from the campaigns, and engage potential supporters. Moreover, the election itself was narrow in focus with two main events: the first round and the run-off election. This means that the professional brokers not only had a goal but also a deadline to focus their resources and efforts. Similarly, IF was a coordinated campaign focusing on a small number of key events and issues. Each of the participating organizations, though varied in their level of resources, may have served as professional brokers whose primary aim was engaging the sector and the broader public by transmitting relevant information across them.

On the other hand, the OWS movement was more organic in its origins. The demonstrators themselves tried to foster the idea of a "leaderless revolution" and aimed to keep momentum for a long period of time. There were few singular events that served to focus their resources and activities and the way in which they organized, both locally and globally, was explicitly designed to foster egalitarian and horizontal interactions. Analyzed at a more local scale, the results from the Occupy show different patterns. Although in some cases the trend was similar to the aggregate movement, in other cases, local networks show higher levels of coordination and intergroup interaction. After accounting for geographical conditions, we believe that these results support $\mathrm{H} 4$, that is, organizations play a key role in fostering brokerage in collective action networks.

To test our first hypothesis, that the three observed networks are different from random, we compared the mean scores for closure and brokerage for the random simulations against each network. The results - in Online Appendix A-show that in most cases, the difference between observed and random networks is not due to chance, providing strong support for H1.

For $\mathrm{H} 3$, the results are consistent with our expectations. In all three events analyzed, the correlation between brokerage and closure is positive. ${ }^{4}$ The detailed results can be found in Online Appendix B, along with figures for each of the networks. We used both parametric (Pearson's $R$ ) and nonparametric (Kendall's $\tau$ ) measures of association to test the hypothesis. In summary, brokerage and closure appear to be positively correlated in all three cases, although it becomes weaker in the case of the OWS data set, mainly for the above discussed reasons. 
The findings from the OWS, the IF campaign and the Chilean election provide a compelling account of the formation of social capital online. The three cases show patterns of behavior that cannot be explained fully by the most widely used theoretical models nor respond to mere random allocation of nodes and ties. In sum, the data suggest evidence of social capital formation online.

\section{Conclusion}

In this article, we have provided initial evidence of the formation of social capital in online networks. We return to Putnam's concepts of bonding and bridging social capital in reviewing our findings. With regard to bonding social capital, online interactions appear to bring together like-minded people, and create small, dense groups among them. That is, the potential of ICTs to create bonding social capital is better than of the theoretical models. On the positive side, this means that online networks may have more potential than we expected to foster the creation of trust and reciprocity, based on the idea of intra-group ties. However, this may also lead to what Putnam calls "cyberbalkanisation," keeping like-minded people together, and not allowing the members of the groups to be exposed to more diverse information, while excluding those outside of them.

In terms of the bridging social capital, the results are conditional. It seems that the presence of organizations and professional brokers in the networks allows for bridging across structural holes. That is, the formation of bridging social capital seems possible by the presence of people whose aim is to produce those ties. The connection between small groups does not occur randomly or organically. In essence, this is not much different than what we would expect according to Bennett and Segerberg's typology. The alleged horizontal and spontaneous nature of online interactions might not be enough to produce, without intention, bridging social capital. Moreover, these results support Gibson and McAllister's findings about the prevalence of bonding over bridging social capital in online environments. Our tests using observational networks - instead of self-reported data-provides an "acid test" for the veracity of their conclusions.

Putnam also claims that healthy societies foster the formation of both bonding and bridging social capital in coordination. One is required for the presence and operation of the other, and as such, the interplay between them creates trust, appreciation for diversity, and communication among different social groups. Our results show that online interactions are able to produce the same positive interplay. Furthermore, the evidence presented also provides support to the idea that this positive interplay requires intentionality. Online social capital seems to be in the right direction, allowing and fostering the coordination between bridging and bonding social capital. However, this 
is also present in events where part of the ethos of the network is the communication across people from different groups.

We have focused our attention here on the online social architecture, the networks of twitter connections and conversations, to test whether we observe evidence for patterns of bridging and bonding social capital. One thing we have not tested is whether the content of the conversations and connections provide evidence for social capital in the sense of building trust and norms. This, in our view, is the clearest and most pressing area for future research. There is an important distinction between the thinner, transactional view of connective action (Bennett \& Segerberg, 2013) and the thicker, transformational view of social capital. The crucial next step is to understand if, when, where, and how connections beget positive social externalities and help form the "social glue" of Putnam (2001). In this light, we see our more modest and structural contribution here as a necessary first step in this endeavor. Because social capital cannot exist in "the ether" but requires social bonds - online or offline - we argue that we have provided the necessary, but not sufficient, first step in understanding whether social capital exists in online networks.

This article has attempted to provide a preliminary approach to the formation of social capital in online contexts, by analyzing three different Twitter data sets. Our findings suggest that the current theoretical expectations of how social connections are created and maintained are not able to explain the network structure of online social interactions. Furthermore, on the question of the existence of social capital in online settings, we fall on the side of caution. Online connections seem able to easily create bonding social capital, but they require a concentrated effort to create bridges across those groups. The ideal setting presented by Putnam, where bonding and bridging social capital operate in conjunction, requires intention and effort.

\section{Authors' Note}

Any errors found remain the responsibility of the authors.

\section{Acknowledgments}

We thank colleagues for feedback and comments received during different presentations of this article. In particular, we thank the participants at talks given at Universidad de Chile, Universidad Adolfo Ibañez, and Universidad Católica. We would also like to thank Dave Karpf, David Rotschild, and Jonathan Nagler for their comments and suggestions.

\section{Declaration of Conflicting Interests}

The author(s) declared no potential conflicts of interest with respect to the research, authorship, and/or publication of this article. 


\section{Funding}

Tha data from the IF campaign was funded by David Hudson's 2013 British Academy Mid Career Fellowship.

\section{Notes}

1. Bridging and bonding social capital may not be sufficiently nuanced categories for characterizing online interactions, given the absence of cues that help to structure group formation in face-to-face environments. Before developing more nuanced categories, however, it is useful to determine whether traditional conceptualizations are present.

2. Each data set contains the text of the tweet, date, and time, the user who sent it (username and user identification number), and relevant metadata, such as location and the profile image of the sender.

3. As a plausible explanation, we could argue that Occupy movements radicalized in smaller, not mainstream cities, might benefit from more local, offline organization. Hence, the levels of brokerage might look more dynamic and higher.

4. As explained above, the way in which network constraint is measured is such that higher levels of brokerage is expressed in lower levels of network constraint. For that reason, we use $1-\bar{C}$.

\section{References}

Appel, L., Dadlani, P., Dwyer, M., Hampton, K., Kitzie, V., Matni, Z. A., . . . Teodoro, R. (2014). Testing the validity of social capital measures in the study of information and communication technologies. Information, Communication \& Society, 17, 398-416.

Bennett, W. L., \& Segerberg, A. (2013). The logic of connective action: Digital media and the personalization of contentious politics. New York, NY: Cambridge University Press.

Bimber, B., Flanagin, A., \& Stohl, C. (2012). Collective action in organizations: Interaction and engagement in an era of technological change. Cambridge, UK: Cambridge University Press.

Bond, R. M., Fariss, C. J., Jones, J. J., Kramer, A. D. I., Marlow, C., Settle, J. E., \& Fowler, J. H. (2012). A 61-million-person experiment in social influence and political mobilization. Nature, 489, 295-298.

Bourdieu, P. (1986). The forms of capital. In J. G. Richardson (Ed.), Handbook of theory and research for the sociology of education (pp. 241-258). New York, NY: Greenwood Press.

Bowles, S., \& Gintis, H. (2002). Social capital and community governance. The Economic Journal, 112, F419-F436.

Brundidge, J., \& Rice, R. (2009). Political engagement online: Do information rich get richer and the like-minded more similar. In A. Chadwick \& P. N. Howard 
(Eds.), Routledge handbook of internet politics (pp. 144-156). New York, NY: Taylor \& Francis

Burt, R. (2000). The network structure of social capital. Research in Organizational Behavior, 22, 345-423.

Burt, R. (2005). Brokerage and closure: An introduction to social capital. New York, NY: Oxford University Press.

Castells, M. (2012). Networks of outrage and hope: Social movements in the internet age. Cambridge, UK: Polity Press.

Chomsky, N. (2012). Occupy. London, England: Penguin.

Christakis, N. A., \& Fowler, J. H. (2011). Connected: The surprising power of our social networks and how they shape our lives-How your friends' friends' friends affect everything you feel, think, and do (Reprint ed.). London, England: Back Bay Books.

Claridge, T. (2004). Social capital and natural resource management (Unpublished doctoral dissertation). University of Queensland, Brisbane, Australia.

Clements, K. (2011). Social media: The twilight years of fundraising. BMJ Supportive \& Palliative Care, 1, 252.

Coleman, J. S. (1988). Social capital in the creation of human capital. The American Journal of Sociology, 94, S95-S120.

Colletta, N. J., \& Cullen, M. L. (2000). Violent conflict and the transformation of social capital: Lessons from Cambodia, Rwanda, Guatemala, and Somalia. Washington, DC: World Bank Publications.

Conover, M. D., Davis, C., Ferrara, E., McKelvey, K., Menczer, F., \& Flammini, A. (2013). The geospatial characteristics of a social movement communication network. PLoS ONE, 8(3), e55957.

Conover, M. D., Ferrara, E., Menczer, F., \& Flammini, A. (2013). The digital evolution of Occupy Wall Street. PLoS ONE, 8(5), e64679.

Darnton, A., \& Kirk, M. (2011). Finding frames: New ways to engage the UK public in global poverty. London, England: Bond.

de Tocqueville, A. (2006). Democracy in America. Fairford, UK: Echo Library.

DiGrazia, J., McKelvey, K., Bollen, J., \& Rojas, F. (2013). More tweets, more votes: Social media as a quantitative indicator of political Behavior. PloS ONE, 8(11), e79449.

Ellison, N., Steinfield, C., \& Lampe, C. (2006). The benefits of Facebook "friends": Social capital and college students' use of online social network sites. Journal of Computer Mediated Communication, 12, 1143-1168.

Ellison, N., Steinfield, C., \& Lampe, C. (2011). Connection strategies: Social capital implications of Facebook-enabled communication practices. New Media \& Society, 13, 873-892.

Fábrega, J., \& Sajuria, J. (2014). The emergence of political discourse on digital networks: The case of the occupy movement. International Journal of Organisational Design and Engineering, 3, 210-222. 
Gibson, R. K., Howard, P. N., \& Ward, S. J. (2000). Social capital, internet connectedness and political participation: A four-country study. In International Political Science Association Meeting. Quebec, Canada

Gibson, R. K., \& McAllister, I. (2013). Online social ties and political engagement. Journal of Information Technology \& Politics, 10, 21-34.

González-Bailón, S., Borge-Holthoefer, J., Rivero, A., \& Moreno, Y. (2011). The dynamics of protest recruitment through an online network. Scientific Reports, 1, Article 197.

Granovetter, M. S. (1973). The strength of weak ties. The American Journal of Sociology, 78, 1360-1380.

Hanifan, L. J. (1920). The community center. Boston, MA: Nabu Press.

Hooghe, M., \& Stolle, D. (2003). Generating social capital: Civil society and institutions in comparative perspective. London, England: Palgrave Macmillan.

Judge, S., Puckett, K., \& Bell, S. M. (2006). Closing the digital divide: Update from the early childhood longitudinal study. The Journal of Educational Research, 100, 52-60.

Kavanaugh, A. L., \& Patterson, S. J. (2001). The impact of community computer networks on social capital and community involvement. American Behavioral Scientist, 45, 469-509.

Kwon, M.-W., D’Angelo, J., \& McLeod, D. M. (2013). Facebook use and social capital to bond, to bridge, or to escape. Bulletin of Science, Technology \& Society, $33,35-43$.

Lin, N. (2008). A network theory of social capital. In D. Castiglione, J. W. van Deth, \& G. Wolleb (Eds.), The handbook of social capital (pp. 50-69). New York, NY: Oxford University Press

Margetts, H., John, P., Escher, T., \& Reissfelder, S. (2011). Social information and political participation on the internet: An experiment. European Political Science Review, 3, 321-344.

McAdam, D. (1990). Freedom summer. New York, NY: Oxford University Press.

McCallister, L., \& Fischer, C. S. (1978). A procedure for surveying personal networks. Sociological Methods \& Research, 7, 131-148.

McCarthy, J. D., \& Zald, M. N. (1977). Resource mobilization and social movements: A partial theory. American Journal of Sociology, 82, 1212-1241.

McPherson, M., Smith-Lovin, L., \& Cook, J. M. (2001). Birds of a feather: Homophily in social networks. Annual Review of Sociology, 27, 415-444.

Morozov, E. (2011). The net delusion: How not to liberate the world. London, England: Penguin.

Morstatter, F., Pfeffer, J., Liu, H., \& Carley, K. M. (2013). Is the sample good enough? Comparing data from twitter's streaming API with Twitter's Firehose. In Proceedings of ICWSM

Olson, M. (1965). The logic of collective action: Public goods and the theory of groups. Cambridge, MA: Harvard University Press.

Pinchotti, S., \& Verwimp, P. (2007). Social capital and the Rwandan genocide: A micro-level analysis. Brighton, UK 
Portes, A. (1998). Social capital: Its origins and applications in modern sociology. Annual Review of Sociology, 24, 1-24.

Putnam, R. (1994). Making democracy work: Civic traditions in modern Italy. Princeton, NJ: Princeton University Press.

Putnam, R. (2001). Bowling alone: The collapse and revival of American community. New York, NY: Simon \& Schuster.

Rainie, L., \& Smith, A. (2012). Social networking sites and politics (Vol. 12, Tech. Rep.). Washington, DC: Pew Internet \& American Life Project.

Shah, D. V., Kwak, N., \& Holbert, L. (2001). "Connecting" and "Disconnecting" with civic life: Patterns of internet use and the production of social capital. Political Communication, 18, 141-162.

Shen, C., Monge, P., \& Williams, D. (2014). Virtual brokerage and closure: Network structure and social capital in a massively multiplayer online game. Communication Research, 41, 459-480.

Sobel, J. (2002). Can we trust social capital? Journal of Economic Literature, 40, 139-154.

Tufekci, Z. (2014). The medium and the movement: Digital tools, social movement politics, and the end of the free rider problem. Policy Internet, 6, 202-208.

Tzanakis, M. (2013). Social capital in Bourdieu's, Coleman's and Putnam's theory: Empirical evidence and emergent measurement issues. Educate, 13(2), 2-23.

Vaccari, C., Valeriani, A., Barberá, P., Bonneau, R., Jost, J. T., Nagler, J., \& Tucker, J. (2013). Social media and political communication: A survey of twitter users during the 2013 Italian general election. Rivista Italiana di Scienza Politica, 43, 381-410.

Van Der Gaag, M., \& Snijders, T. (2005). The resource generator: Social capital quantification with concrete items. Social Networks, 27, 1-29.

Ward, S., \& Gibson, R. (2009). European political organizations and the internet: Mobilization, participation, and change. In A. Chadwick \& P. N. Howard (Eds.), Routledge handbook of internet politics (pp. 25-39). New York, NY: Taylor \& Francis

Watts, D., \& Strogatz, S. (1998). Collective dynamics of a "small world" networks. Nature, 393, 440-442.

Webber, M. P. (2008). Access to social capital and the course of depression: A prospective study (Doctoral thesis). King's College London, London.

Wellman, B., Haase, A., Witte, J., \& Hampton, K. (2001). Does the internet increase, decrease, or supplement social capital? Social networks, participation, and community commitment. American Behavioral Scientist, 45, 436-455.

Williams, D. (2006). On and Off the net: Scales for social capital in an online era. Journal of Computer-Mediated Communication, 11, 593-628.

Yardi, S., \& boyd, D. (2010). Dynamic debates: An analysis of group polarization over time on Twitter. Bulletin of Science, Technology \& Society, 30, 316-327 